Citation: V. Guarnaccia, I. Martino, L. Brondino, A. Garibaldi, M.L. Gullino (2021) Leaf anthracnose and defoliation of blueberry caused by Colletotrichum helleniense in Northern Italy. Phytopathologia Mediterranea 60(3): 479-491. doi: 10.36253/phyto-12377

Accepted: July 28, 2021

Published: December 30, 2021

Copyright: @ 2021 V. Guarnaccia, I. Martino, L. Brondino, A. Garibaldi, M.L. Gullino. This is an open access, peerreviewed article published by Firenze University Press (http://www.fupress. $\mathrm{com} / \mathrm{pm}$ ) and distributed under the terms of the Creative Commons Attribution License, which permits unrestricted use, distribution, and reproduction in any medium, provided the original author and source are credited.

Data Availability Statement: All relevant data are within the paper and its Supporting Information files.

Competing Interests: The Author(s) declare(s) no conflict of interest.

Editor: Josep Armengol Forti, Polytechnical University of Valencia, Spain.

\section{Research Papers \\ Leaf anthracnose and defoliation of blueberry caused by Colletotrichum helleniense in Northern Italy}

\author{
Vladimiro GUARNACCIA ${ }^{1,2, *}$, Ilaria MARTINO ${ }^{1}$, Luca BRONDINO ${ }^{3}$, \\ Angelo GARIBALDI ${ }^{1}$, MARIA Lodovica GULLINO ${ }^{1}$ \\ ${ }^{1}$ Centre for Innovation in the Agro-Environmental Sector, AGROINNOVA, University of \\ Torino, Largo Braccini 2, 10095 Grugliasco (TO), Italy \\ ${ }^{2}$ Department of Agricultural, Forest and Food Sciences (DISAFA), University of Torino, \\ Largo Braccini 2, 10095 Grugliasco (TO), Italy \\ ${ }^{3}$ Ortofruit Italia Soc. Agr. Coop. O.P., Via Colombaro dei Rossi 16/bis, 12037 Saluzzo \\ (CN), Italy \\ ${ }^{*}$ Corresponding author. E-mail: vladimiro.guarnaccia@unito.it
}

Summary. Highbush blueberry is an increasingly important crop due to its economic value and demonstrated health benefits of blueberries. Leaf spots are considered as minor diseases of blueberry plants, but they adversely affect blueberry productivity, causing reduced photosynthetic activity, flower bud formation and berry production. Surveys of blueberry crops were conducted in Piedmont, Northern Italy, during 2019-2020. Fungi isolated from leaf spots of the blueberry cultivar 'Blue Ribbon' were identified as Colletotrichum helleniense through a robust multi-locus phylogeny. Eight genomic loci were considered: tub, gapdh, act, cal, his3, chs-1, ApMat and gs. Morphological characters of a representative strain were assessed. Pathogenicity was confirmed on four blueberry cultivars, although with different levels of aggressiveness to the cultivars. This study shows the importance of a polyphasic approach to investigate species of Colletotrichum, and the relevance of molecular tools for the species-level characterization within the 'Kahawae' clade. This is the first report of Colletotrichum helleniense causing leaf anthracnose on Vaccinium corymbosum.

Keywords. Vaccinium corymbosum, multi-locus typing, berry fruit.

\title{
INTRODUCTION
}

Highbush blueberry (Vaccinium corymbosum, Ericaceae) is an increasingly important crop in Italy, with Piedmont, Veneto and Trentino Alto Adige as the major production areas (Brazelton, 2011). During the last decade, new cultivars and modern agricultural practices have been adopted, resulting in consistent improvement in berry production in Italy, with 1.675 tons harvested from 172 ha in 2018 (FAOSTAT 2019). Increasing emphasis on healthy life-styles and the recognition of blueberries as natural functional food have favoured berryfruit consumption and influenced the increased world produc- 
tion (Polashock et al., 2017; Romo-Muñoz et al., 2019). However, this led to increased global movement and trade of plant materials, resulting in the spread of pathogens and emergence of new diseases (Polashock et al., 2017; Guarnaccia et al., 2020; Liu et al., 2020).

Anthracnose is one of the most economically important diseases of blueberry (Retamales and Hancock, 2018), and the most frequent and relevant disease of blueberry fruit is anthracnose caused by Colletotrichum spp. However, shoot tip blight and leaf spot caused by the same pathogens are included among the additional symptoms, and could develop during growing seasons. Leaf symptoms could reduce photosynthesis, cause premature defoliation and affect subsequent flower bud formation (Polashock et al., 2017). Species of Colletotrichum have been reported in association with anthracnose on blueberry leaves in different international regions (Farr and Rossman, 2020). Several Colletotrichum spp. are important plant pathogens, affecting a wide range of hosts in different climatic regions (Dean et al., 2012). Assessment of morphological features of these fungi has been the common method to classify species within Colletotrichum. However, adoption of molecular approaches has allowed profound taxonomic revision of the genus (Weir et al., 2012; Cabral et al., 2020). Previous studies based on morphological features ascribed the species causing blueberry anthracnose mainly to the Colletotrichum acutatum species complex (SC), (C. acutatum sensu stricto, C. fioriniae, C. nymphaeae), C. gloeosporioides SC (C. fructicola, C. gloeosporioides sensu stricto, C. kahawae, C. siamense), C. boninense SC (C. karstii) and C. orchidearum SC (C. sichuaninese) (Hartung et al., 1981; Barrau et al., 2001; Kim et al., 2009; Xu et al., 2013; Rios et al., 2015; Pszczolkowska et al., 2016; Ali et al., 2019; Liu et al. 2020). Liu et al. (2020) reported Colletotrichum fructicola as the dominant species affecting blueberry leaves in Sichuan Province, China, followed by Colletotrichum siamense, C. kahawae, C. karstii, C. nymphaeae and C. sichuaninese. Species of Colletotrichum gloeosporioides SC were responsible for blueberry leaf spot in China (Xu et al., 2013), Korea (Kim et al., 2009), Georgia (Ali et al., 2019) and the United States of America (Hartung et al., 1981). Species of the Colletotrichum acutatum SC were found in association with leaf anthracnose in Australia (Shivas et al., 2009; 2016), Canada (Verma et al., 2006), China (Xu et al., 2013), Japan (Yoshida and Tsukiboshi, 2002; Yoshida et al., 2007), Korea (Kim et al., 2009), New Zealand (Pennycook, 1989; Gadgil et al., 2005), Poland (Pszczółkowska et al., 2016), Spain (Barrau et al., 2001), The Netherlands (Nirenberg et al., 2002) and the United States of America (Guerber et al., 2003). Rios et al. (2015) reported Colletotrichum karstii in association with blueberry leaf spots in Brazil. However, since these species could persist as sources of inoculum in the field, affecting orchards and possibly cross-infecting other nearby crops while switching to a pathogenic lifestyles, specific pathogen identification should be provided (Fuentes-Aragón et al., 2020). Currently, molecular data are combined with morphological characters and pathogenicity tests in a polyphasic approach to clearly identify species within the Colletotrichum SC (Guarnaccia et al., 2019, 2021a; Damm et al., 2019).

Leaf anthracnose of blueberry bushes was observed in Piedmont, Northern Italy. The aims of the present study were: i) to characterize fungi isolated from this disease using morphological, molecular and phylogenetic tools, and ii) to test their pathogenicity to fulfil Koch's postulates.

\section{MATERIALS AND METHODS}

\section{Field sampling and fungus isolation}

Surveys were conducted from March to September 2019 in two blueberry plantations in Cuneo, Piedmont,

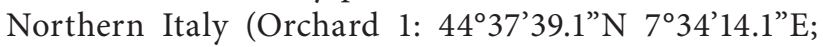
Orchard 2: $\left.44^{\circ} 38^{\prime} 20.3^{\prime \prime} \mathrm{N} 7^{\circ} 31^{\prime} 23.8^{\prime \prime} \mathrm{E}\right)$. Anthracnose incidence (DI) was assessed based on the percentage of affected plants. Ten symptomatic leaves were randomly collected from about twenty plants. Portions of symptomatic leaves $(5-10 \mathrm{~mm})$ were surface sterilised in $1 \%$ sodium hypochlorite for $1 \mathrm{~min}$, rinsed in sterile distilled water (SDW) for $1 \mathrm{~min}$ and dried on sterile absorbent paper. Small fragments $(2-3 \mathrm{~mm})$ were cut from lesion margins and plated on potato dextrose agar (PDA, Merck) amended with $25 \mathrm{ppm}$ of streptomycin sulphate (PDA-S, Sigma-Aldrich). The plates were incubated at 25 $\pm 1^{\circ} \mathrm{C}$ under a $12 \mathrm{~h}$ photoperiod. Following 48 to $72 \mathrm{~h}$ of incubation, sporulating conidiomata obtained were collected and crushed in drops of sterile water and then spread over the surface of PDA-S plates. After $24 \mathrm{~h}$, germinating spores were individually transferred onto PDA plates. Ten isolates were obtained and two of these were used for molecular characterization (Table 1). Stock cultures are maintained at $-80^{\circ} \mathrm{C}$ at the Agroinnova Centre of Competence, University of Torino, Torino, Italy.

DNA extraction, polymerase chain reaction (PCR) amplification, and sequencing

DNA was extracted from two isolates with an E.Z.N.A. Fungal DNA Mini Kit (Omega Bio-Tek, 


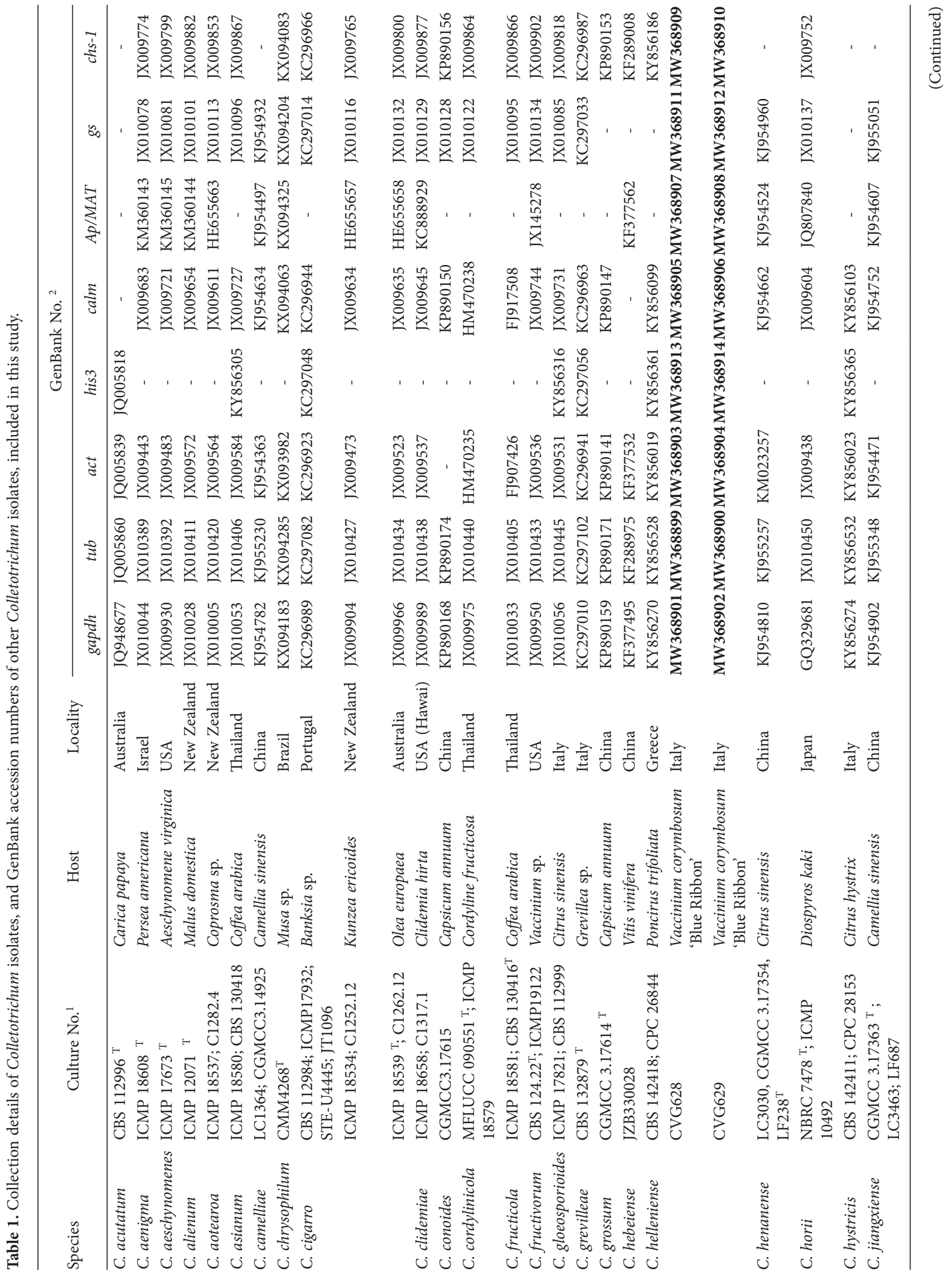




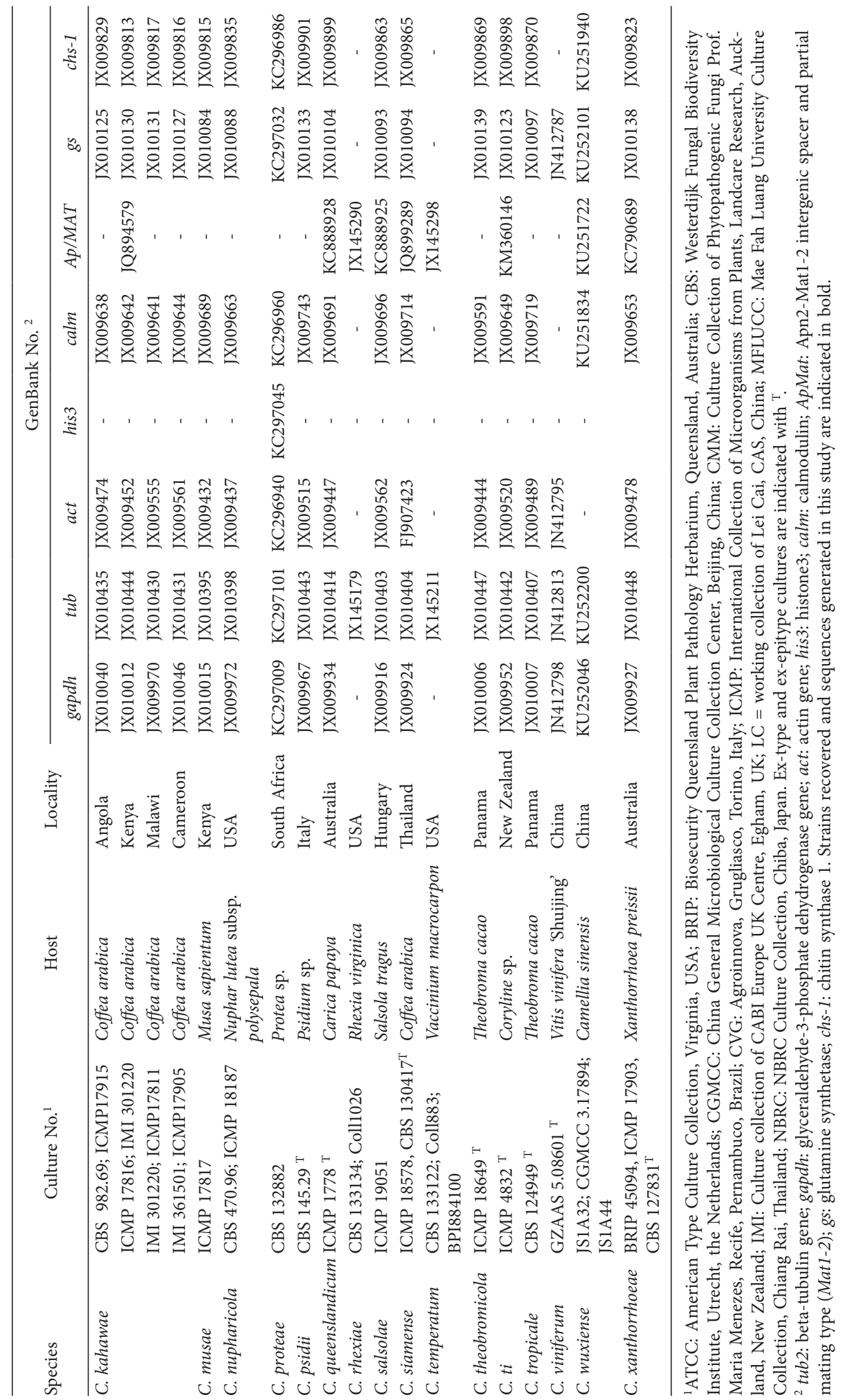


Darmstadt, Germany) from $0.1 \mathrm{~g}$ of mycelium grown on PDA, following the minikit manufacturer's instructions. Species identification was achieved by DNA sequencing of a combined dataset of eight genomic loci, including beta-tubulin ( $t u b 2)$, glyceraldehyde3-phosphate dehydrogenase (gapdh), actin (act), calmodulin (cal), histone3 (his3), chitin synthase 1 (chs-1), Apn2-Mat1-2 intergenic spacer and partial mating type (Mat1-2) (ApMat), and glutamine synthetase ( $g s$ ). The primers used for each locus shown in Table 2. The amplification mixtures of PCR and respective cycling conditions of Guarnaccia et al. (2017) were used for the tub2, gapdh, act, cal, his3 and chs-1 regions. The gs partial gene and Mat1-2/ApMat region were amplified using the PCR protocols of Liu et al. (2015). Five $\mu \mathrm{L}$ of PCR product for each PCR reaction was examined by electrophoresis at $100 \mathrm{~V}$ on $1 \%$ agarose (VWR Life Science AMRESCO ${ }^{\circ}$ biochemicals) gels stained with GelRed ${ }^{\mathrm{TM}}$. PCR products were sequenced in both directions by Eurofins Genomics Service. The generated sequences were analysed and consensus sequences were computed using the program Geneious v. 11.1.5 (Auckland, New Zealand).

\section{Phylogenetic analyses}

New sequences obtained in this study were blasted against the NCBI's GenBank nucleotide database to determine the closest relatives for a taxonomic framework of the studied isolates. Alignments of differ- ent gene regions, including sequences obtained from this study and sequences downloaded from GenBank, were initially performed with the MAFFT v. 7 online server (http://mafft.cbrc.jp/alignment/server/index. html) (Katoh and Standley 2013), and then manually adjusted in MEGA v. 7 (Kumar et al., 2016). The phylogenies were based on Maximum Parsimony (MP) and Bayesian Inference (BI) for the multi-locus analyses. The MP analyses were performed using Phylogenetic Analysis Using Parsimony (PAUP) v.4.0b10 (Swofford, 2003). Phylogenetic relationships were estimated by heuristic searches with 100 random addition sequences. Tree bisection-reconnection was used, with the branch swapping option set on 'best trees', with all characters weighted equally and alignment gaps treated as fifth state. Tree length (TL), consistency index (CI), retention index (RI) and rescaled consistence index (RC) were calculated for parsimony, and the bootstrap analyses (Hillis and Bull, 1993) were based on 1000 replications. Sequences generated in this study were deposited in GenBank (Table 1). For BI, the best evolutionary model for each partition was determined using MrModeltest v. 2.3 (Nylander, 2004) and incorporated into the analyses. MrBayes v. 3.2.5 (Ronquist et al., 2012) was used to generate phylogenetic trees under optimal criteria per partition. The Markov Chain Monte Carlo (MCMC) analysis used four chains and started from a random tree topology. The heating parameter was set at 0.2 and trees were sampled every 1000 generations. Analyses stopped when the average standard deviation of split frequencies was less than 0.01 .

Table 2. Primers used in this study.

\begin{tabular}{|c|c|c|c|}
\hline Locus & Primer name & Primer sequence $5^{\prime}->3^{\prime}$ & Reference \\
\hline \multirow[t]{2}{*}{ tub } & $\mathrm{T} 1$ & AACATGCGTGAGATTGTAAGT & Glass and Donaldson, 1995 \\
\hline & Bt $2 b$ & ACCCTCAGTGTAGTGACCCTTGGC & O’Donnell and Cigelnik, 1997 \\
\hline \multirow[t]{2}{*}{ gapdh } & GDF1 & GCCGTCAACGACCCCTTCATTGA & Guerber et al. 2003 \\
\hline & GDR1 & GGGTGGAGTCGTACTTGAGCATGT & \\
\hline \multirow[t]{2}{*}{ act } & ACT-512F & ATGTGCAAGGCCGGTTTCGC & Carbone and Kohn, 1999 \\
\hline & ACT-783R & TAGGAGTCCTTCTGACCCAT & \\
\hline \multirow[t]{2}{*}{$\mathrm{cal}$} & CL1 & GARTWCAAGGAGGCCTTCTC & O’Donnell et al., 2000 \\
\hline & CL2 & TTTTTGCATCATGACCCTTGGC & \\
\hline \multirow[t]{2}{*}{ his3 } & CYLH3F & GCAACATCTCGTCCGCTCT & Crous et al., 2004 \\
\hline & CYLH3R & AGCTGGATGTCCTTGGACTG & \\
\hline \multirow[t]{2}{*}{ chs } & CHS-79F & TGGGGCAAGGATGCCTGGAAGAAG & Carbone and Kohn, 1999 \\
\hline & CHS-345R & TGGAAGAACCATCTGTGGGAGTTG & \\
\hline \multirow[t]{2}{*}{ ApMat } & AMF1 & TCATTCTACGTATGTGCCCG & Silva et al., 2012 \\
\hline & AMR1 & CCAGAAATACACCGAACTTGC & \\
\hline \multirow[t]{2}{*}{ gs } & GSF1 & ATGGCCGATACATCTGG & Stephenson et al., 1997 \\
\hline & GSR1 & GAACCGTCGAAGTTCCAC & \\
\hline
\end{tabular}




\section{Isolate morphology}

Agar plugs (5 $\mathrm{mm}$ diam.) of the strains CVG628 and CVG629 were taken from the edges of actively growing cultures on PDA-S and were transferred onto the centres of Petri dishes (9 cm diam.) containing PDA, then incubated at $25 \pm 1^{\circ} \mathrm{C}$ under $12 \mathrm{~h}$ photoperiod for $7 \mathrm{~d}$. Three cultures plates of each strain were investigated. Colony characters and diameters were observed/measured after $7 \mathrm{~d}$. Cultures were examined over time for development of ascomata, conidiomata and setae. The morphological characteristics of the fungi were examined by mounting structures in water, and 30 measurements at $400 \times$ magnification were determined for each isolate using a microscope (Nikon Eclipse 55i).

\section{Pathogenicity testing}

The pathogenicity of a representative strain CVG629 was tested on detached leaves of each of the four blueberry cultivars 'Blue Ribbon', 'Duke', 'Last Call' and 'Top Shelf'. Thirty leaves of each cultivar were inoculated and 30 leaves were used as controls. Each leaf was disinfested in a $1 \%$ sodium hypochlorite solution for 60 s followed by three washes of $60 \mathrm{~s}$ in sterile distilled water and blot dried on sterile absorbent paper before inoculation. The leaves were placed in plastic plates $(12.5 \times 12.5 \times 1.5$ $\mathrm{cm}$ [length $\times$ width $\times$ height]) with wet sterile absorbent paper to create a humid chambers. Each leaf was slightly wounded with a sterile needle and then inoculated with $10 \mu \mathrm{L}$ of a conidium suspension $\left(10^{6}\right.$ conidia $\mathrm{mL}^{-1}$ ) obtained from a 10d-old culture of the representative isolate grown on PDA. Sterile distilled water was used for the control leaves. The plates were incubated at $25 \pm 1^{\circ} \mathrm{C}$ under $12 \mathrm{~h}$ photoperiod for 7 days. The strains CVG628 and CVG629 were also tested in planta on attached leaves of the same cultivars. A total of $20 \mathrm{~mL}$ of a conidium suspension, obtained as described before, was sprayed on wounded and unwounded leaves. Six plants of each cultivar were used, and three of these were wounded with a sterile needle. A further six plants were similarly treated but spayed with sterile water as experimental controls. The plants were covered with a transparent plastic film to keep high relative humidity, and were transferred to a growth chamber and kept at $25^{\circ} \mathrm{C}$ with a $12 \mathrm{~h}$ photoperiod. The plastic film was removed $3 \mathrm{~d}$ post inoculation (dpi). Each trial was repeated once. Data of the replications of the repeated experiments were pooled and analysed together for each trial. Disease severity was evaluated $7 \mathrm{dpi}$ for the trial on detached leaves or $10 \mathrm{dpi}$ for the attached leaves, using a diagrammatic scale for percentage of infected leaf area
(Gullino et al., 2017). The scale was: symptomless leaf (0); up to $5 \%$ infected leaf area (1); 6 to $10 \%$ (2); 11 to $25 \%$ (3); 26 to $50 \%$ (4); and 51 to $100 \%$ (5). Disease severity (DS) was calculated as DS $=\Sigma$ (no. of leaves $\times \mathrm{X}_{0-5}$ )/ (no. of leaves), where $\mathrm{X}_{0-5}$ refers to an approximate class midpoint as follows: $\mathrm{X}_{0}=0 ; \mathrm{X}_{1}=3 \% ; \mathrm{X}_{2}=8 \% ; \mathrm{X}_{3}=18 \%$; $\mathrm{X}_{4}=38 \% ; \mathrm{X}_{5}=76 \%$. Because no normal distribution was observed, the data were analysed using Kruskal-Wallis non-parametric test (at $P=0.05$ ) to determine significant differences among the tested cultivars. The data analyses were conducted using SPSS software 26 (IBM Corporate). The identity of the re-isolated strains was confirmed through sequencing the gapdh and gs loci, to fulfil Koch's postulates.

\section{RESULTS}

\section{Field sampling and fungus isolation}

Symptoms identified as those typically caused by Colletotrichum spp. were found in two blueberry plantations of the cultivars 'Blue Ribbon' and 'Last Call'. Disease incidence was assessed at $20 \%$, considering the percentage of affected plants. The symptoms observed consisted of brown-to-black, necrotic lesions occurring on mature leaves grown on 1-year-old twigs (Figure 1). Stem defoliation occurred. Based on colony aspect and growth, and conidial morphology characteristics, the fungal strains isolated from symptomatic leaves collected during the surveys were ascribed to Colletotrichum spp. and pure fungal cultures were obtained.

\section{Phylogenetic analyses}

The combined locus phylogeny of Colletotrichum consisted of 46 sequences. A total of 3749 characters (tub2: 1-510, gapdh: 517-795, act: 802-1030, cal: 1037-1655, his3: 1662-2040, chs-1: 2047-2250, ApMat: 2257-2927 and gs: 2934-3749) were included in the phylogenetic analyses. A maximum of 1000 equally most parsimonious trees were saved, and characteristics of the combined gene partitions used for each phylogenetic analysis are reported in Table 3. Bootstrap support values from the parsimony analysis were plotted on the Bayesian phylogenies (Figure 2). For the Bayesian analyses, MrModel test recommended the models in Table 3. Unique site patterns for each partition and all the parameters of the Bayesian analyses are reported in Table 3. In the generated phylogenetic tree, the strains isolated from Vaccinium plants clustered with the extype reference strain of $C$. helleniense, within the 'Kaha- 

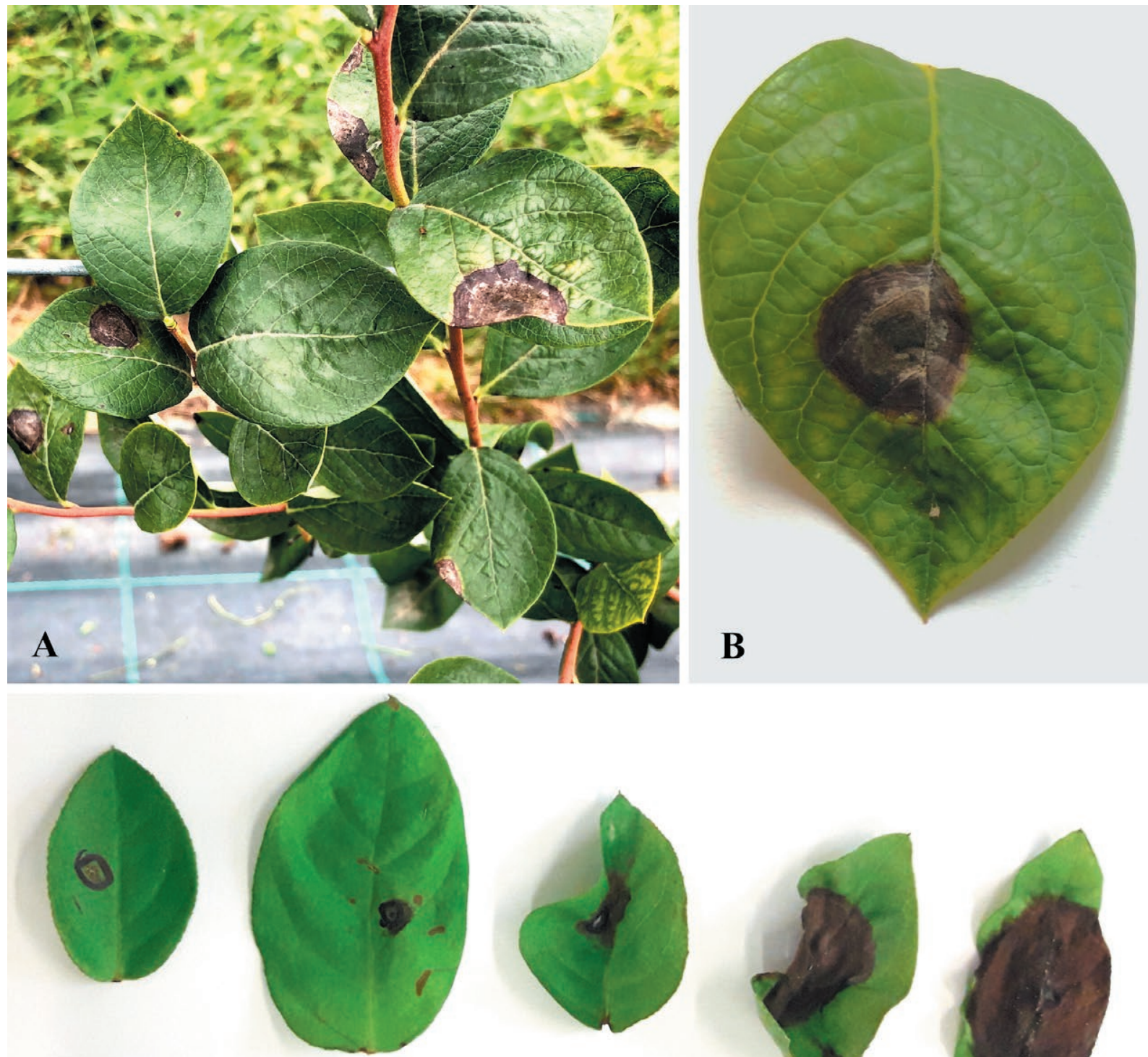

C
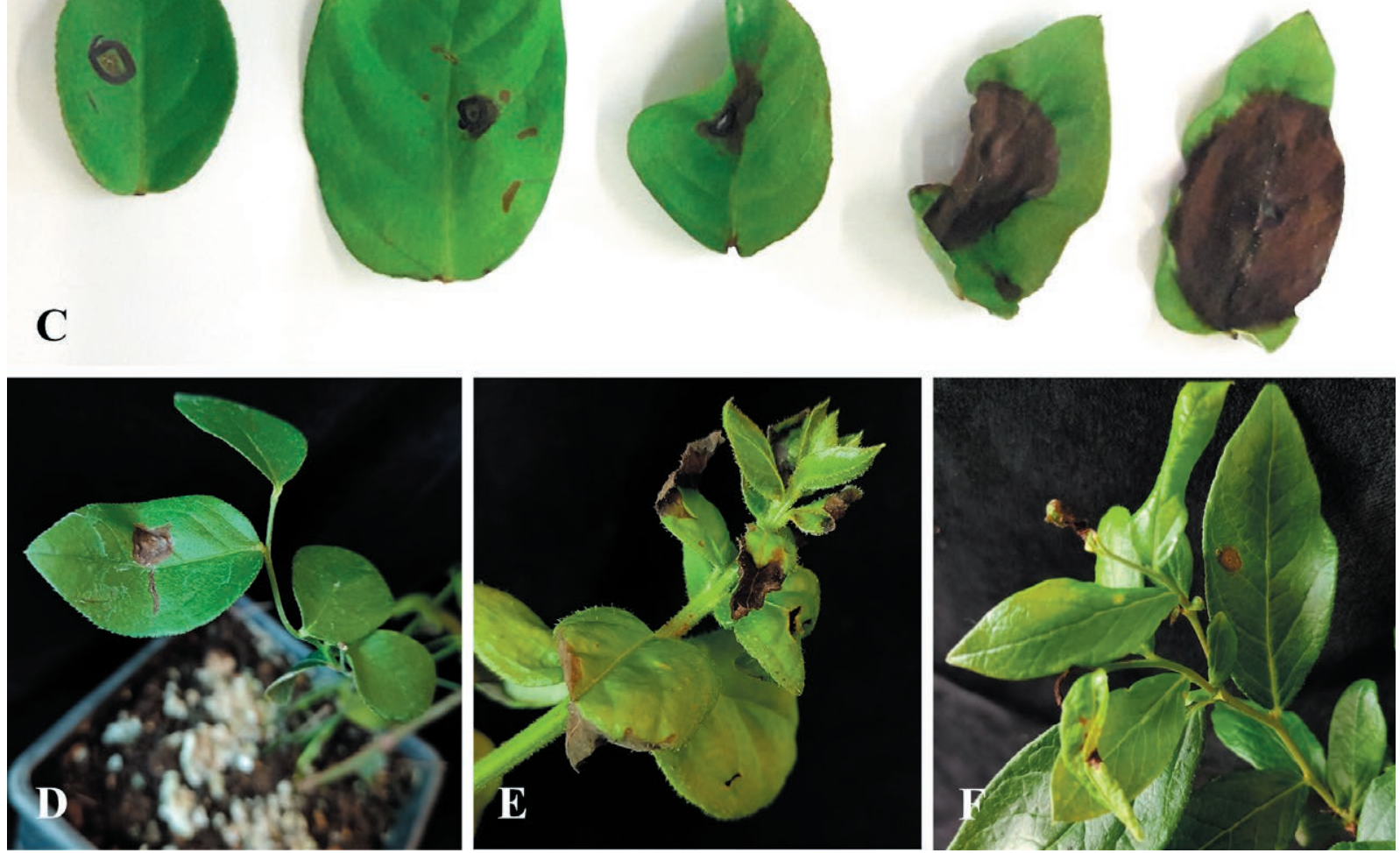

Figure 1. Leaf anthracnose (A and B) of Vaccinium corymbosum 'Blue Ribbon' in the field, and leaves of 'Last Call' at different necrotic stages after inoculation (C). Anthracnose developed after inoculations on 'Last Call' wounded (D and F) and unwounded (E) attached leaves. 
Table 3. Maximum Parsimony, evolutionary models and Bayesian analysis characteristics of this study.

\begin{tabular}{|c|c|c|c|c|c|c|c|c|c|c|c|}
\hline $\begin{array}{l}\text { Parsimony } \\
\text { analysis }\end{array}$ & Total sites & $\begin{array}{c}\text { Constant } \\
\text { sites }\end{array}$ & $\begin{array}{l}\text { Variable } \\
\text { sites }\end{array}$ & $\begin{array}{c}\text { Parsimony } \\
\text { informative } \\
\text { sites }\end{array}$ & $\begin{array}{c}\text { Tree } \\
\text { length }\end{array}$ & $\begin{array}{c}\text { Consistency } \\
\text { index }\end{array}$ & $\begin{array}{l}\text { Retention } \\
\text { index }\end{array}$ & $\begin{array}{l}\text { Rescaled } \\
\text { consistence } \\
\text { index }\end{array}$ & - & - & - \\
\hline \multirow{3}{*}{$\begin{array}{l}\text { Evolutionary } \\
\text { model }\end{array}$} & 3707 & 2066 & 973 & 668 & 2634 & 0.784 & 0.865 & 0.678 & - & - & - \\
\hline & tub2 & gapdh & Act & cal & his3 & chs- 1 & ApMat & $g s$ & - & - & - \\
\hline & $\mathrm{SYM}+\mathrm{G}$ & K80 & HKY & $\mathrm{SYM}+\mathrm{G}$ & $\mathrm{HKY}+\mathrm{G}$ & $\mathrm{K} 80+\mathrm{G}$ & $\mathrm{K} 80+\mathrm{G}$ & $\mathrm{GTR}+\mathrm{G}$ & - & - & - \\
\hline \multirow[t]{2}{*}{ Bayesian analysis } & $\begin{array}{l}\text { U.S.P. }^{1} \\
\text { tub2 }\end{array}$ & $\begin{array}{l}\text { U.S.P. } \\
\text { gapdh }\end{array}$ & U.S.P. $a c t$ & U.S.P. cal & U.S.P. his3 & $\begin{array}{l}\text { U.S.P. } \\
\text { chs-1 }\end{array}$ & $\begin{array}{l}\text { U.S.P. } \\
\text { ApMat }\end{array}$ & U.S.P. $g s$ & $\begin{array}{c}\text { Generation } \\
\text { ran }\end{array}$ & $\begin{array}{l}\text { Generated } \\
\text { trees }\end{array}$ & $\begin{array}{c}\text { Sampled } \\
\text { trees }\end{array}$ \\
\hline & 156 & 188 & 97 & 130 & 52 & 42 & 269 & 296 & 8.315 .000 & 8316 & 6237 \\
\hline
\end{tabular}

${ }^{1}$ U.S.P.: Unique Site Patterns.

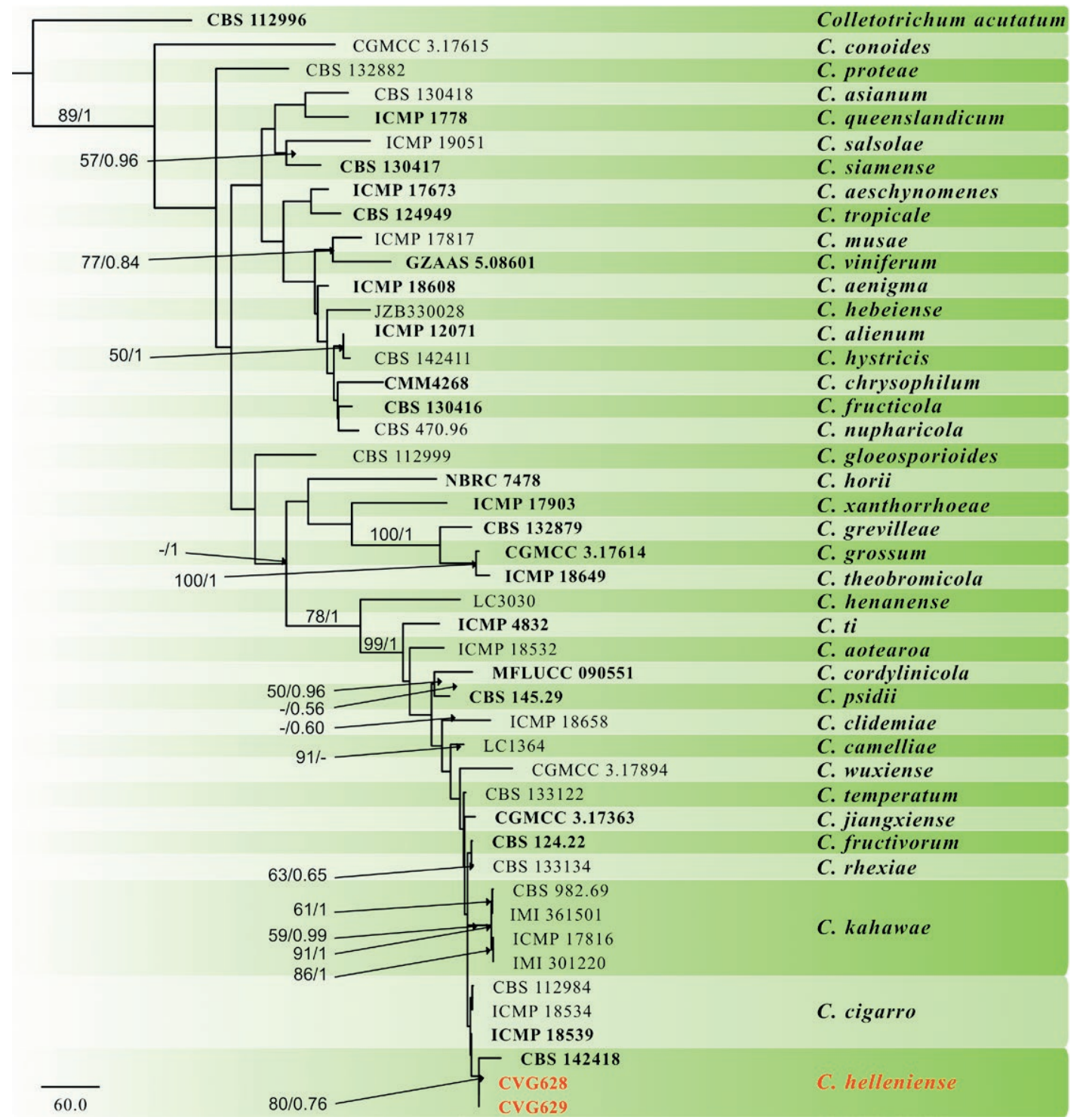

Figure 2. Maximum parsimony (MP) best-tree phylograms obtained from 46 Colletotrichum gloeosporioides species complex strains. Numbers on the nodes are MP bootstrap and Bayesian posterior probability values. Isolates obtained from Vaccinium in the present study are indicated in red font. Ex-type strains are indicated in bold. The tree was rooted to Colletotrichum acutatum (CBS 112996). 

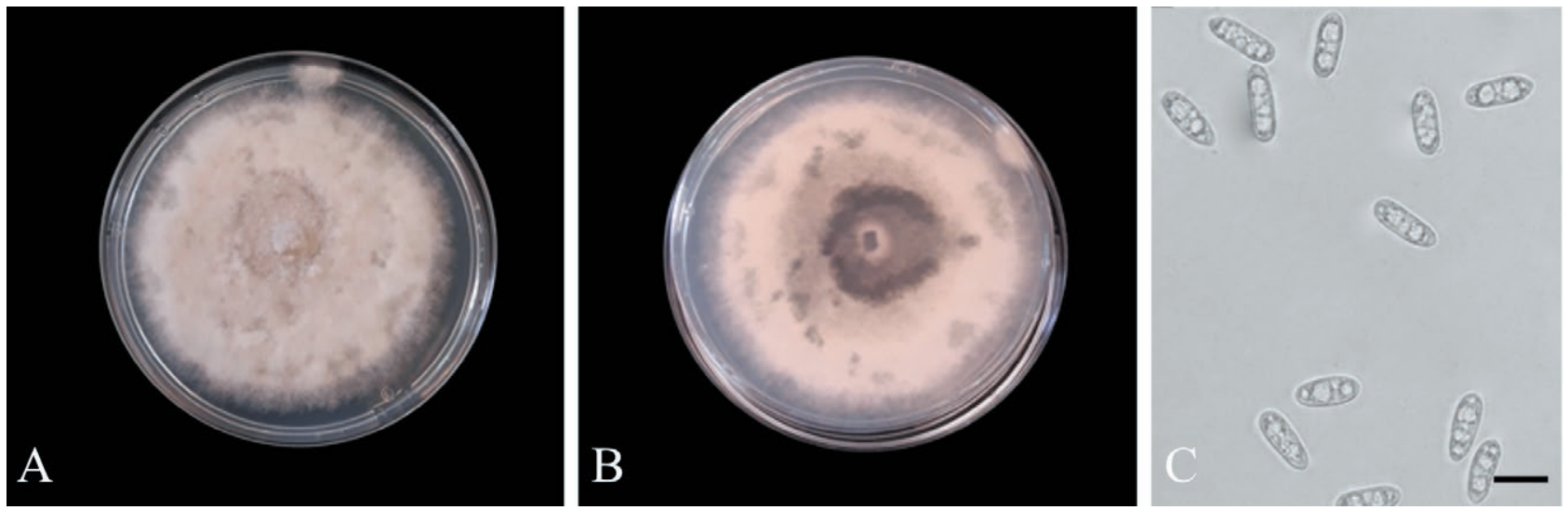

Figure 3. Front (A) and reverse (B) sides of a Colletotrichum helleniense colony (CVG629 strain) grown for $7 \mathrm{~d}$ on PDA, and conidia (C). Scale bar $=10 \mu \mathrm{m}$.

wae' clade and closely related with C. cigarro, C. fructivorum, C. jiangxiense, C. kahawae, C. rhexiae and C. temperatum.

\section{Morphology}

Morphological observations, supported by phylogenetic inference, were used to describe the representative strain of Colletotrichum helleniense (Figure 3).

Asexual morph on PDA: Conidiomata acervular. Hyphae hyaline, septate and branched. Setae not observed. Conidia hyaline, aseptate, cylindrical with rounded apices and bases, guttulate, mean dimensions $12.2 \pm 1.4 \times 5.0 \pm 0.5 \mu \mathrm{m}$ for the strain CVG628 and 13.5 $\pm 1.5 \times 4.5 \pm 0.5 \mu \mathrm{m}$ for CVG629. Colonies on PDA with entire margins, grey in the centres and white to pale buff at the margins, entirely covered with floccose to dense, white to grey aerial mycelium, and with black conidiomata. Conidia present in pinkish-salmon-orange masses. Reverse of colonies grey to pale luteous, mean diam. after $7 \mathrm{~d}=80 \mathrm{~mm}$ for strain CVG628 and $79 \mathrm{~mm}$ for CVG629.

\section{Pathogenicity tests}

The strains were pathogenic when inoculated on detached leaves, and on wounded and unwounded attached leaves of all the blueberry cultivars tested, although with different levels of aggressiveness (Figures 4 and 5). Symptoms on the leaves consisted of dark brown necrotic spots expanding circularly from the point of inoculation. The pathogenic strains were reisolated from inoculated leaves, and were identified as described above by blast analysis of the gapdh and $g s$ loci. This fulfilled Koch's postulates for the two assessed

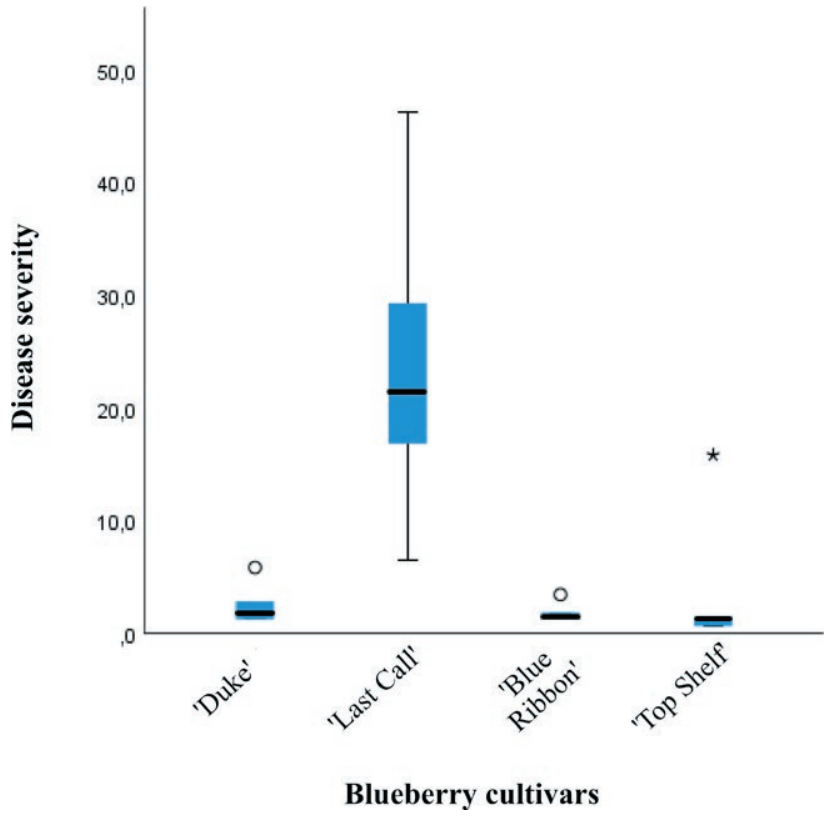

Figure 4. Box plot of results of pathogenicity tests on detached blueberry leaves. Boxes represent the interquartile range, and the horizontal line within each box indicates the average value. The Kruskal-Wallis test was used to compare the mean leaf areas infected after inoculations of four cultivars, and significant differences were accepted at $P<0.05$.

strains. In test with detached leaves, the pairwise comparison obtained from the Kruskal-Wallis test showed differences $(P<0.05)$ in susceptibility between 'Last Call' and the other three cultivars (Supplementary Table 1). No differences $(P>0.05)$ were observed among 'Blue Ribbon', 'Duke' and 'Top Shelf'. In the test with attached leaves, the pairwise comparison showed differences $(P$ $<0.05$ ) only between 'Blue Ribbon' and 'Top Shelf' and 


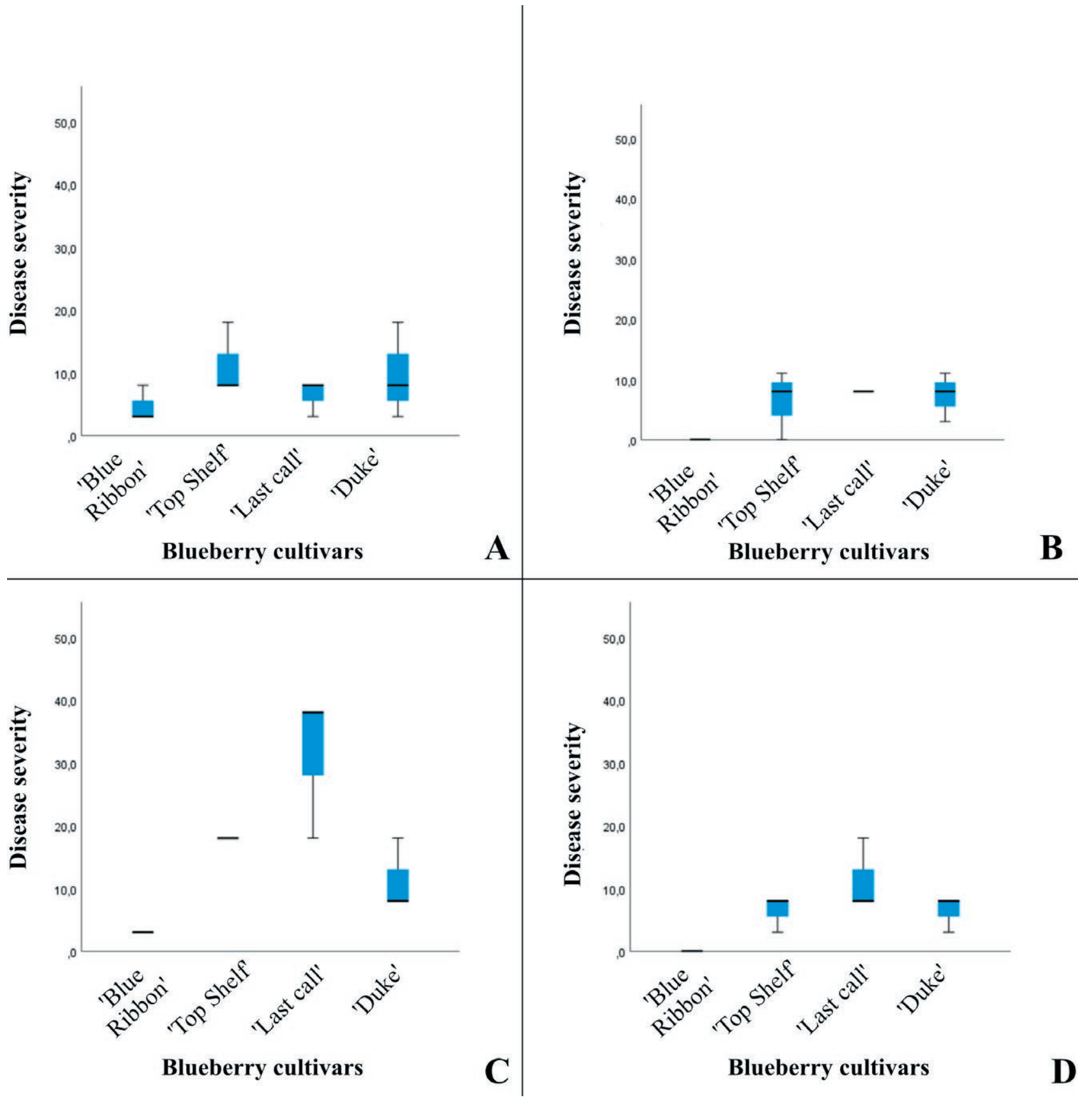

Figure 5. Box plots showing the results of the pathogenicity tests on wounded attached blueberry leaves (A with strain CVG628 and C with CVG629), and on unwounded attached leaves (B with strain CVG628 and D with CVG629). Boxes represent the interquartile range, and the horizontal line within each box indicates the average value. The Kruskal-Wallis test was carried used to compare the mean leaf areas infected after inoculations on four cultivars, and significant differences were accepted at $P<0.05$.

'Last Call', and between 'Duke' and 'Last Call', and this was only for leaves wounded and inoculated with the strain CVG629 (Supplementary Table 2). The strain CVG628 gave high severity on 'Top Shelf', 'Last Call' and 'Duke' with no difference between wounded and unwounded leaves. The strain CVG629 caused weak symptoms on wounded and unwounded 'Blue Ribbon' leaves, but very severe symptoms on wounded 'Last Call' leaves. No symptoms were observed on control leaves in the detached or attached leaf pathogenicity assays. 


\section{DISCUSSION}

Different Colletotrichum spp. have been reported in association with anthracnose diseases on several fruit crops, where pre- and post-harvest fruit rots are the most common symptoms observed and the most investigated diseases (Dean et al., 2012). However, leaf spots also represent a serious threat to fruit production (Benjamin, 2018; Guarnaccia et al., 2021b). Necrotic leaf lesions caused by Colletotrichum have been reported on blueberry plants, resulting in defoliation and reduced berry yields (Retamales and Hancock, 2018).

The present study is the first investigation of blueberry anthracnose conducted in the major production area of Italy. Since previous Colletotrichum studies were based on morphological characterization and ITS region analyses, which were insufficient for species identification (Cai et al., 2009), eight different genomic loci have been considered to provide robust multi-locus phylogenies and are useful tools for analyses of target loci for Colletotrichum spp. classification. The fungus strains isolated in the present study were identified as Colletotrichum helleniense, a species in the C. kahawae clade within the C. gloeosporioides SC. Colletotrichum helleniense has been described by Guarnaccia et al. (2017) in association with Citrus reticulata fruit lesions and with Poncirus trifoliata whither-tip twigs in Greece. The different reported hosts of $C$. helleniense confirms the pathogen's broad host range. This potential cross-infection ability combined with the complex life cycles of Colletotrichum spp. increases the difficulties for managing anthracnose diseases (De Silva et al., 2017). Cabral et al. (2020) provided taxonomic clarification within the 'Kahawae' clade to distinguish C. kahawae from $C$. cigarro comb. et stat. nov. Pathological, morphological, cytogenomic and biochemical data were combined with analysis of a nine-locus concatenated dataset including the ApMat and $g s$ regions. These genomic regions, reported by Cabral et al. (2020) as useful to identify Colletotrichum spp. within the C. gloeosporioides SC, were considered to analyse the isolated Colletotrichum spp. investigated in the present study. This is the first report of Colletotrichum helleniense on Vaccinium corymbosum in Italy, as well as worldwide. However, further studies are required to provide insight on the species members of the 'Kahawae' clade based on genome sequencing, and to ascertain differentiation between $C$. cigarro and C. helleniense.

The pathogenicity tests reported here have confirmed the aggressiveness of $C$. helleniense, although the four assessed blueberry cultivars showed different susceptibilities to leaf anthracnose. Colletotrichum infections usually start with conidium germination and appressorium production on host tissues. However, direct penetration through stomata or wounds with no appressoria has also been reported, for example, during the infection process of mulberry leaves by C. gloeosporioides (De Silva et al., 2017). The present study demonstrates the ability of $C$. helleniense to cause anthracnose with and without wounds on attached blueberry leaves. All the cultivars tested were susceptible to the pathogen. However, 'Blue Ribbon' was generally less susceptible, while 'Last Call' developed more severe symptoms, confirming the results obtained from the inoculations on detached leaves. Different climate factors such as hail, rain and freezing, common in the surveyed area of Italy, can induce lesion development on leaves and are abiotic stress factors having potential roles in the disease development. Further studies should be conducted to assess the roles of climate factors and environment conditions on blueberry anthracnose. The pathogenicity results obtained in the present study need to be integrated with further experiments conducted at different temperatures and humidities.

After a first investigation of wood diseases and losses of production caused by several fungal pathogens (Guarnaccia et al., 2020), the present study provides new insights on the phytosanitary status of blueberry crops in Northern Italy. Considering the economic relevance of blueberry in this area, further research is required to determine the possible roles of other fungi, the epidemiology of the involved pathogens, and their responses to the currently adopted disease management protocols. This research should aim to establish new effective and sustainable disease management strategies for blueberry crops.

\section{ACKNOWLEDGEMENTS}

This study was supported by the Foundation CRT in the project "Avversità del MIRtillo in Piemonte: dove e come combAtteRlE (MIRARE)". The authors thank Dr G. Tabone (AGROINNOVA, University of Torino) for the technical support.

\section{LITERATURE CITED}

Ali M.E., Hudson O., Hemphill W.H., Brenneman T.B., Oliver J.E., 2019. First report of resistance to pyraclostrobin, boscalid, and thiophanate-methyl in Colletotrichum gloeosporioides from blueberry in Georgia. Plant Health Progress 20: 261-262. 
Barrau C., De los Santos B., Romero F., 2001. First report of Colletotrichum acutatum in blueberry plants in Spain. Plant Disease 85: 1285.

Benjamin E., 2018. Biotecnology for Fruit Crop Improvement. Scientific e-Resources, $352 \mathrm{pp}$.

Brazelton C., 2011. World blueberry acreage and production report. US Highbush Blueberry Council 1-51.

Cabral A., Azinheira H.G., Talhinhas P., Batista D., Ramos A.P., ... Várzea V., 2020. Pathological, morphological, cytogenomic, biochemical and molecular data support the distinction between Colletotrichum cigarro comb. et stat. nov. and Colletotrichum kahawae. Plants 9: 502.

Cai L., Hyde K.D., Taylor P.W.J., Weir B., Waller J., ... Prihastuti H., 2009. A polyphasic approach for studying Colletotrichum. Fungal Diversity 39: 183-204.

Carbone I., Kohn L.M., 1999. A method for designing primer sets for speciation studies in filamentous ascomycetes. Mycologia 91: 553-556.

Crous P.W., Groenewald J.Z., Risède J.M., Simoneau P., Hywel-Jones N.L., 2004. Calonectria species and their Cylindrocladium anamorphs: species with sphaeropedunculate vesicles. Studies in Mycology 50: 415-430.

Damm U., Sato T., Alizadeh A., Groenewald J.Z., Crous P.W., 2019. The Colletotrichum dracaenophilum, C. ámagnum and $C$. áorchidearum species complexes. Studies in Mycology 92: 1-46.

Dean R., Van Kan J.A., Pretorius Z.A., HammondKosack, K.E., Di Pietro A., ... Foster G.D., 2012. The Top 10 fungal pathogens in molecular plant pathology. Molecular Plant Pathology 13: 414-430.

De Silva D.D., Crous P.W., Ades P.K., Hyde K.D., Taylor P.W., 2017. Life styles of Colletotrichum species and implications for plant biosecurity. Fungal Biology Reviews 31: 155-168.

FAOSTAT, 2019. Food and Agriculture Organization of the United Nations http://www.fao.org/faostat/ en/\#home. Accessed on November 2020.

Farr D.F., Rossman A.Y., 2020. Fungal Databases U.S. National Fungus Collections ARS USDA.

Fuentes-Aragón D., Guarnaccia V., Rebollar-Alviter A., Juárez-Vázquez S.B., Aguirre-Rayo F., Silva-Rojas H.V., 2020. Multilocus identification and thiophanate-methyl sensitivity of Colletotrichum gloeosporioides species complex associated with fruit with symptoms and symptomless leaves of mango. Plant Pathology 69: 1125-1138.

Gadgil P.D., Dick M.A., Hood I.A., Pennycook S.R., 2005. Fungi on Trees and Shrubs in New Zealand (Vol. 4). Fungal Diversity Press.

Glass N.L., Donaldson G.C., 1995. Development of primer sets designed for use with the PCR to amplify con- served genes from filamentous ascomycetes. Applied and Environmental Microbiology 61: 1323-1330.

Guarnaccia V., Groenewald J.Z., Polizzi G., Crous P.W., 2017. High species diversity in Colletotrichum associated with citrus diseases in Europe. Persoonia: Molecular Phylogeny and Evolution of Fungi 39: 32-50.

Guarnaccia V., Gilardi G., Martino I., Garibaldi A., Gullino M.L., 2019. Species diversity in Colletotrichum causing anthracnose of aromatic and ornamental Lamiaceae in Italy. Agronomy 9: 613.

Guarnaccia V., Martino I., Tabone G., Brondino L., Gullino M.L., 2020. Fungal pathogens associated with stem blight and dieback of blueberry in northern Italy. Phytopathologia Mediterranea 59: 229-245.

Guarnaccia V., Martino I., Gilardi G., Garibaldi A., Gullino, M.L., 2021a. Colletotrichum spp. causing anthracnose on ornamental plants in Northern Italy. Journal of Plant Pathology 103: 127-137.

Guarnaccia V., Peduto Hand F., Garibaldi A., Gullino M.L., 2021b. Bedding plant production and the challenge of fungal diseases. Plant Disease in press, DOI:10.1094/PDIS-09-20-1955-FE.

Guerber J.C., Liu B., Correll J.C., Johnston P.R., 2003. Characterization of diversity in Colletotrichum acutatum sensu lato by sequence analysis of two gene introns, mtDNA and intron RFLPs, and mating compatibility. Mycologia 95: 872-895.

Gullino M.L., Gilardi G., Garibaldi A., 2017. Evaluating severity of leaf spot of lettuce, caused by Allophoma tropica, under a climate change scenario. Phytopathologia Mediterranea. 56: 235-241.

Hartung J.S., Burton C.L., Ramsdell D.C., 1981. Epidemiological studies of blueberry anthracnose disease caused by Colletotrichum gloeosporioides. Phytopathology 71: 449-453.

Hillis D.M., Bull J.J., 1993. An empirical test of bootstrapping as a method for assessing confidence in phylogenetic analysis. Systematic Biology 42: 182-192.

Katoh K., Standley D.M., 2013. MAFFT Multiple sequence alignment software version 7: improvements in performance and usability. Molecular Biology and Evolution 30: 772-780.

Kim W.G., Hong S.K., Choi H.W., Lee Y.K., 2009. Occurrence of anthracnose on highbush blueberry caused by Colletotrichum species in Korea. Mycobiology 37: 310-312.

Kumar S., Stecher G., Tamura K., 2016. MEGA7: Molecular Evolutionary Genetics Analysis version 7.0 for bigger datasets. Molecular Biology and Evolution 33: 1870-1874.

Liu F., Weir B.S., Damm U., Crous P.W., Wang Y., ... Cai L., 2015. Unravelling Colletotrichum species associ- 
ated with Camellia: employing ApMat and GS loci to resolve species in the C. gloeosporioides complex. Persoonia: Molecular Phylogeny and Evolution of Fungi 35: 63.

Liu X., Zheng X., Khaskheli M.I., Sun X., Chang X., Gong G., 2020. Identification of Colletotrichum species associated with blueberry anthracnose in Sichuan, China. Pathogens 9: 718.

Nirenberg H.I., Feiler U., Hagedorn G., 2002. Description of Colletotrichum lupini comb. nov. in modern terms. Mycologia 94: 307-320.

Nylander J.A.A., 2004. MrModeltest v. 2. Program distributed by the author. Uppsala Evolutionary Biology Centre Uppsala University.

O’Donnell K., Cigelnik E., 1997. Two divergent intragenomic rDNA ITS2 types within a monophyletic lineage of the fungus Fusarium are nonorthologous. Molecular Phylogenetics and Evolution 7: 103-116.

O’Donnell K., Nirenberg H.I., Aoki T., Cigelnik E., 2000. A multigene phylogeny of the Gibberella fujikuroi species complex: detection of additional phylogenetically distinct species. Mycoscience 41: 61-78.

Pennycook S.R., 1989. Plant Diseases Recorded in New Zealand. Volumes 1, 2 and 3. Plant Diseases Division, DSIR.

Polashock J.J., Caruso F.L., Averill A.L., Schilder A.C., 2017. Compendium of Blueberry Cranberry and Lingonberry Diseases and Pests, 2nd edn. APS Press St. Paul.

Pszczółkowska A., Okorski A., Paukszo Ł., Jastrzębski, J., 2016. First report of anthracnose disease caused by Colletotrichum fioriniae on blueberry in western Poland. Plant Disease 100: 2167-2167.

Retamales J.B., Hancock J.F., 2018. Blueberries, 2nd edition. CABI, Wallingford, UK.

Rios J.A., Pinho D.B., Moreira W.R., Pereira O.L., Rodrigues F.A., 2015. First report of Colletotrichum karstii causing anthracnose on blueberry leaves in Brazil. Plant Disease 99: 157-157.

Romo-Muñoz R.R., Dote-Pardo J.D., Garrido-Henríquez H.G., 2019. Blueberry consumption and healthy lifestyles in an emerging market. Spanish Journal of Agricultural Research 17: e0111.

Ronquist F., Teslenko M., Van der Mark P., Ayres D.L., Darling A., ... Huelsenbeck J.P., 2012. MrBayes 3.2: efficient Bayesian phylogenetic inference and model choice across a large model space. Systematic Biology 61: 539-542.

Shivas R.G., Yu Y.P., 2009. A taxonomic re-assessment of Colletotrichum acutatum, introducing C. fioriniae comb. et stat. nov. and C. simmondsii sp. nov. Fungal Diversity 39: e122.
Shivas R.G., Tan Y.P., Edwards J., Dinh Q., Maxwell A., ... Coates L.M., 2016. Colletotrichum species in Australia. Australasian Plant Pathology 45: 447-464.

Silva D.N., Talhinhas P., Várzea V., Cai L., Paulo O.S., Batista D., 2012. Application of the Apn2/MAT locus to improve the systematics of the Colletotrichum gloeosporioides complex: an example from coffee (Coffea spp.) hosts. Mycologia 10: 396-409.

Stephenson S.A., Green J.R., Manners J.M., Maclean D.J., (1997). Cloning and characterisation of glutamine synthetase from Colletotrichum gloeosporioides and demonstration of elevated expression during pathogenesis on Stylosanthes guianensis. Current Genetics 31: 447-454.

Swofford D.L., 2003. PAUP*. Phylogenetic analysis using parsimony (*and other methods) v. 4.0b10. Sinauer Associates Sunderland Massachusetts.

Verma N., MacDonald L., Punja Z.K., 2006. Inoculum prevalence, host infection and biological control of Colletotrichum acutatum: causal agent of blueberry anthracnose in British Columbia. Plant Pathology 55: $442-450$.

Weir B.S., Johnston P.R., Damm U., 2012. The Colletotrichum gloeosporioides species complex. Studies in Mycology 73: 115-180.

Xu C.N., Zhou Z.S., Wu Y.X., Chi F.M., Ji Z.R., Zhang H.J., 2013. First report of stem and leaf anthracnose on blueberry caused by Colletotrichum gloeosporioides in China. Plant disease 97: 845-845.

Yoshida S., Tsukiboshi T., 2002. Shoot blight and leaf spot of blueberry anthracnose caused by Colletotrichum acutatum. Journal of General Plant Pathology: JGPP 68: 246.

Yoshida S., Tsukiboshi T., Shinohara H., Koitabashi M., Tsushima S., 2007. Occurrence and development of Colletotrichum acutatum on symptomless blueberry bushes. Plant Pathology 56: 871-877. 